\title{
Spatial variability in pollen and resource limitation for fruit production of two species in interior Alaska: Vaccinium uliginosum and V. vitis-idaea
}

\author{
Lindsey Viann Parkinson*, Christa P.H. Mulder
}

Institute of Arctic Biology and Department of Biology and Wildlife, University of Alaska Fairbanks, Fairbanks, Alaska, USA

*Corresponding author

Email: parkinson.lindsey@protonmail.com 


\begin{abstract}
Many recent studies assessing fruit productivity of plants in the boreal forest focus on interannual variability across a forested region, rather than on environmental variability within the forest. Frequency and severity of wildfires in the boreal forest affect soil moisture, canopy, and community structure at the landscape level, all of which may influence overall fruit production at a site directly (through resource availability) or indirectly (through impacts on pollinators). We evaluated how fruit production in two boreal shrubs, Vaccinium uliginosum (blueberry) and $V$. vitis-idaea (lingonberry), was explained by factors associated with resource availability (such as canopy cover and soil conditions) and pollen limitation (such as floral resources for pollinators and pollen deposition) across boreal forest sites of Interior Alaska. We classified our study sites into upland and lowland sites, which differed in elevation, soil moisture (lower in upland sites), and active layer (deeper in upland sites). We found that resource and pollen limitation differed between the two species and between uplands and lowlands. Lingonberry was more pollen limited than blueberry, and plants in lowland sites were more pollen limited relative to other sites while plants in upland sites were relatively more resource limited. Additionally, canopy cover had a significant negative effect in upland sites on a ramet's investment in reproductive tissues and leaves versus structural growth, but little effect in lowland sites. These results point to importance of including pollinator abundance as well as resource availability in predictions for changes in berry abundance.
\end{abstract}




\section{Introduction}

At least 50 species of plants produce fleshy fruits (hereafter: "berries") in Alaska [1] In Interior Alaska, a region bordered by the Alaska Range to the south and the Brooks Range to the north, Vaccinium vitis-idaea L. (lingonberry, cowberry, partridgeberry, lowbush cranberry, hereafter: lingonberry) and V. uliginosum L. (lowbush blueberry, bog bilberry, bog blueberry, hereafter: blueberry) are two of the fruits most commonly consumed by both humans and animals [2]. Many species including bears (Ursus spp.), foxes (Vulpes vulpes), geese (e.g., Branta hutchinsii), and voles (e.g., Myodes rutilus) eat the berries [3-7]. Nearly three quarters of all berries collected in rural communities in Interior Alaska in 2015 were from these two species [8]. Berry production is a multi-year process dependent upon weather, pollinator activity, light availability, and soil conditions [9-10]. Recent studies assessing berry production in boreal plants have focused on interannual variability across a region [11-12] but berry production varies spatially within the region as well [13-14]. Due to the multi-year development period of Vaccinium flowers, interannual models of fruit production account for some of the effects of changing weather and climate; however, abiotic factors that affect spatial variability are often overlooked.

Interior Alaska is undergoing rapid climate change, altering not just temperature but also the frequency, severity, and extent of wildfire [15-17]. Understanding how Vaccinium berry production responds to heterogeneous environmental factors such as variation in resource availability (limiting growth and berry development) and variation in pollinator availability (limiting fertilization) within Alaska's boreal forest can provide a foundation for modelling berry crops for humans and animals (i.e. where on the landscape we would expect changes in berry production). Models assessing how changes in wildfire, soil moisture, and permafrost in Interior Alaska may affect plant community structure, already exist [18-20]. However, vegetative plant 
growth and fruit availability are not always correlated [21]. Fruit production in all plants is limited by four factors: 1) resources (e.g., light and soil moisture), 2) pollination, 3) external pulses such as herbivory, disease, or harsh weather, and 4) genetics [22-24]. This paper will focus on resource and pollen limitation.

Slope, aspect, elevation, and fire frequency drive plant community structure in the boreal zone [25-27]. North-facing slopes receive limited sunlight, have cold, poorly drained soils underlain with permafrost, and are primarily composed of Picea mariana (black spruce) stands with a moss understory [25,27]. South facing aspects tend to have warmer, well drained soils occupied by deciduous trees and P. glauca (white spruce) [25-26]. Slope, aspect, and elevation have not changed over the past century, but wildfires are getting larger and returning more quickly across North America's boreal forest regions [15,28-29]. Fire shapes ecosystem dynamics including plant succession and soil condition. In most situations, low shrubs (including many of the berry species of Interior Alaska) are the dominant cover for 10-20 years after a fire, after which tall shrubs and deciduous trees begin to take over and the canopy closes, limiting the light available [30]. If the seed bank survived the wildfire, deciduous trees generally give way to spruce and the canopy opens again [25-26].

Black spruce forests on north facing and lowland sites are typically underlain by permafrost, which leads to cold, wet soils with low nutrient availability [27]. The presence of shallow permafrost cools the soil and inhibits drainage, so water collects from weather events through the growing season as well as from the thawing ground. Fires can remove much of the moss and soil layer that insulates the permafrost, drastically increasing the depth of the active layer (the layer that freezes and thaws annually) depth and thus moisture and temperature 
conditions of the forest stand [16]. We would therefore expect fire history to affect resource availability both by altering the canopy cover and by altering soil moisture and depth of thaw.

A species' ability to efficiently respond to changes in canopy conditions vegetatively may allow for greater investment in reproduction. While they are closely related, blueberries and lingonberries differ in their life history strategy. Lingonberries produce thick, evergreen leaves that last about three years (CPH Mulder, pers. obs.) and replace 39\% of standing biomass each year, while blueberries produce deciduous leaves and have an annual turnover of $62 \%$ standing biomass [31]. Blueberries thus fall closer to the resource acquisitive end of the leaf economic spectrum [32-33] and are potentially able to respond to changes in habitat conditions more quickly than lingonberries, which are on the resource conservative end of the spectrum. We would therefore expect a stronger relationship between canopy cover and investment in reproduction in blueberries than in lingonberries. Similarly, because of their higher nutrient demands, blueberries may be more negatively impacted by low soil nutrients than lingonberries. Environmental variation may affect berry production indirectly through effects on pollinator abundance and activity. Pollinator and floral diversity are low in the boreal forest so many flowers use multiple pollinator species and those pollinators visit many flower species [34]. In Interior Alaska, bumblebees (Bombus spp.), syrphid flies (Syrphidae), and solitary bees (e.g., Adrena spp.) carry the most blueberry and lingonberry pollen [35-36]. High flower density around Vaccinium plants may lure pollinators away from the Vaccinium flower, as suggested by the floral market hypothesis, but could also draw pollinators into the area that otherwise would not have visited [37]. Pollen availability explained the most variation in Finnish bilberry ( $V$. myrtillus) fruit production models [38]. Given the overall low pollinator availability in black spruce forests $[34,39]$, we expected plants in neighborhoods with high total floral resources to 
have greater pollen loads and lower pollen limitation than those in neighborhoods with low total floral resources.

Environmental conditions can also affect pollinator activity. In general, pollinators are expected to be more active in warmer sites; bees are strongly limited by temperature in interior Alaska [40]. However, high canopy cover may also be indicative of good growing conditions for deciduous species, and result in high floral resources, resulting in a complex relationship between canopy cover and pollinator activity.

We assessed the relative effects of light (as indicated by canopy cover), nutrient resources (as indicated by depth of the active layer and soil moisture), and pollen availability (as indicated by pollen load) on flower and berry production in the boreal forest around Interior Alaska. We hypothesized that multiple variables would directly affect berry production and expected interactions among predictors. Specifically:

1. Stand history (time since last fire) was expected to be the primary driver of environmental resource limitation: a longer time since fire was expected to result in greater light limitation.

2. Total floral resources (the number of flowers in the vicinity) was expected to have a positive influence on pollen load, and thus berry production, as a greater number of flowers in the area would attract more pollinators.

3. Blueberry ramets' relative biomass allocation to flowers and fruits was expected to be more responsive to changes in canopy cover than lingonberries' due to the differences in the two plants' life history strategies. We also expected this greater responsiveness to result in greater variability within sites. 


\section{Methods}

Study area and site selection

About one third of the Interior Alaska boreal ecoregion is forested, with $70 \%$ of forest cover dominated by black spruce (Picea mariana Mill.); the rest is primarily white spruce ( $P$. glauca (Moench) Voss), and deciduous trees such as Alaskan birch (Betula neoalaskana Sarg.), quaking aspen (Populus tremuloides Michx.), and balsam poplar (P. balsamifera L.) [41-43]. Ericaceous shrubs such as Labrador tea (Rhododendron groenlandicum L.), blueberry, and lingonberry are dominant species in the understory [1]. This study focused on black spruce stands that span 13 to 200 years since last fire (stand age) and vary in slope, aspect, and forest structure to encompass a variety of growing conditions for Vaccinium (S1 Table). We evaluated berry production at 17 sites within the Bonanza Creek LTER Regional Site Network (Fig 1) where previous surveys found both blueberry and lingonberry ramets [44] and which were accessible by foot or all-terrain vehicle during early summer.

Figure 1. The 17 sites within the Bonanza Creek LTER regional site network used in this study. All sites are within $70 \mathrm{~km}$ of Fairbanks (64.843611, -147.723056) and represent a variety of black spruce forest types. Map credit: GPSvisualizer.com, Megan Perra.

\section{Plant selection}

From the center of each site we marked the nearest flowering Vaccinium ramet to a set of 12 randomly generated coordinates composed of compass degree $\left(0-359^{\circ}\right)$ and distance $(0-20 \mathrm{~m})$, with a search area up to $2 \mathrm{~m}$. If we tagged a ramet too early in the season to distinguish fully between flower and leaf buds, and on the next visit it was clear the ramet was non-reproductive, we moved the tag to the nearest conspecific with distinguishable flower buds. Sites without flowering lingonberry or blueberry within our random points were thoroughly searched and any reproductive blueberry or lingonberry ramets were tagged. We monitored 186 blueberry ramets 
(mean 10.6 tagged reproductive ramets per site, range: 1-12 tagged ramets across sites) and 194 lingonberry ramets (mean: 11.3 tagged reproductive ramets per site, range: 2-12 ramets across the sites) in total. We counted flowers as they developed, and the number of berries produced when the berries at each site began to ripen. Depending on the site and the species, counts took place from mid-July to early August.

\section{Hypothesized drivers of berry production}

We used five variables, measured at the site level, to investigate spatial variability and resource limitation across the landscape: elevation, active layer depth, time since fire (stand age), soil moisture, and soil temperature. Active layer depth and time since fire are both positively related to soil nutrient availability while soil moisture is negatively related to nutrient availability in Interior Alaska [45]. Much of Interior Alaska is underlain by permafrost and is water-logged, creating areas of high soil moisture and low nutrient availability due to anoxia reducing microbial activity [46-47]. Soil temperature and active layer depth are both likely proxies for net mineralization, since cold soils inhibit microbial activity [46]. The presence of shallow permafrost cools the soil and inhibits drainage, so water collects both from weather events through the growing season as well as from the thawing ground [48]. We obtained elevation, time since fire, and active layer depth from the Bonanza Creek LTER data catalog [49]. The LTER team measured active layer depth at 20 points at each site via soil probe in the fall of 2015. We measured soil moisture (\% vol; HH2, Delta-T Devices) and soil temperature (HANNA HI145) in July and August of 2018 at five points across each site, two measurements at each point (four corners and the center for a total of ten measures each visit), after 5 days without rain. Due to weather events and lack of access to sites from poor road conditions after rains or damaged all-terrain vehicles, we could not obtain reliable soil measures in 2017. Since we were 
interested in relative soil moisture and temperature between sites, we averaged the 20

measurements per site for all analyses. To measure canopy cover over each study ramet, we averaged three readings of a concave spherical densiometer measured $2 \mathrm{~cm}$ above the ramet, each reading taken $120^{\circ}$ apart while kneeling. The above variables make up what we will refer to as "environmental variables" (elevation, active layer depth, stand age, soil moisture, and soil temperature).

Flowers on the study plants were counted as soon as they were distinguishable, in late May to early June. Blueberry shrubs can produce over 100 flowers and do not flower all at once, so to avoid double counting on return visits we marked each flower with fabric paint. Other flowering species common in the Interior Alaskan boreal forest that overlap in flowering times include Rhododendron groenlandicum, Chamaedaphne calyculata, Cornus canadensis, and Rubus chamaemorus. We counted total floral resources, defined as all flowers of any species within a $1 \mathrm{~m}$ radius of the focal blueberry ramet or $0.5 \mathrm{~m}$ radius of the focal lingonberry ramet, during peak flowering of the Vaccinium as a measure of the potential for neighborhood plants to attract pollinators to the area or compete with focal plant flowers for resources. $R$.

groenlandicum and C. calyculata produce many flowers per inflorescence and represented the majority of non-Vaccinium floral neighbors. The flowering timing of lingonberry overlapped with the flowering time of $R$. groenlandicum and C. calyculata more than blueberry.

We estimated pollen availability by collecting two pistils from conspecific flowers near each study ramet and estimating pollen loads on the stigmas under a microscope. We attempted to collect pistils during the peak flowering period of each species. Blueberry pistils were collected between June 4 and 26, 2017 and lingonberry pistils between June 11 and 26, 2017. Pistils were mounted on microscope slides in basic fuschin gel [50] within a few days of 
collection. Following Spellman et al. 2015, a ramet was considered "well-pollinated" when the mean number of pollen tetrads on neighboring stigmas was $>10$. Blueberries produce about 45 ovules per flower and lingonberries about 32 in Interior Alaska [40] so 10 pollen tetrads (40 pollen grains) were expected to be enough for fertilization of most or all ovules. It is unknown how many ovules must be fertilized for the plant to create a fruit. We quantified fruit set as the ratio of berries to flowers on a ramet.

\section{Allocation measurements}

Ramets, with their leaves still attached, were dried in an oven for 48 hours before leaves were removed for surface area and mass measurements. Berries from each reproductive plant were placed in a coin envelope while in the field and left in a drying oven for two weeks to ensure complete desiccation. The biomass measurements were used to assess proportion of resources allocated to leaves, stems, and berries. For each ramet we investigated reproductive and vegetative allocation by calculating the ratios of leaf mass to stem mass, flower number to leaf mass, and berry mass to leaf mass.

\section{Statistical Analyses: Structural Equation Models}

We expected environmental variables to be highly correlated, so to categorize the physical environment of the sites we used a principal component analysis (PCA) to sort the sites based on correlations of mean values of the environmental variables: time since fire, elevation, soil moisture, soil temperature, and active layer depth. Missing values were replaced with means from all other sites. We standardized the site averages to a mean of zero and standard deviation of one. The PCA was performed with the built-in R function princomp() [51]. Values for both PCA axes were used as explanatory variables in the structural equation models. 
We created a hypothetical structural equation model (SEM) [52] to assess direct and indirect effects of multiple variables on blueberry and lingonberry fruit production in 2017 (Fig 2). In our a priori model, we collapsed the environmental variables into two indices represented by principal components 1 and 2 (PC1 and PC2), which explained 45\% and 34\% of variation (Fig 3). PC1 was positively correlated with elevation and active layer depth and negatively correlated with soil moisture (Table 1), and reflections position on the landscape. Principle component 2 (PC2) was positively associated with stand age and soil temperature (Table 1) and reflects site history. We used both PC1 and PC2 scores in the SEM model, calling them "geography" and" stand history" respectively.

Fig 2. Hypothesized structural equation model. Response variables are grey. "Environment Geography" consists of correlated factors that differ primarily by position in the landscape, "Environment - Fire" encompasses fire history. Other predictive variables were measured at each Vaccinium ramet.

Table 1. PCA loadings.

\begin{tabular}{lll}
\hline & PC1 & PC2 \\
\hline Soil temperature & --- & $\mathbf{0 . 6 5 1}$ \\
Soil moisture & $\mathbf{- 0 . 5 3 4}$ & -0.157 \\
Active layer depth & $\mathbf{0 . 5 6 3}$ & -0.266 \\
Age & -0.186 & $\mathbf{0 . 6 5 9}$ \\
Elevation & $\mathbf{0 . 5 9 5}$ & 0.216 \\
\hline
\end{tabular}

Principal components 1 and 2 were included in the structural equation model and referred to as Geography and Stand History, respectively.

Since number of flowers limits the number of fruits, we expected a strong positive relationship between the number of flowers produced at the beginning of the season and the number of berries. Canopy cover was expected to affect flower and fruit numbers directly 
through light availability and indirectly by acting as a proxy for local growing conditions.

Finally, we expected geography and stand history to influence the entire plant community in the area.

Prior to fitting the path model, we took the natural log of total floral resources, pollen load, number of flowers, and number of berries produced, to improve adherence to model assumptions. For both species, we first ran a model that included data from all sites. The explanatory power for the focal response variable, number of berries produced was low, especially for lingonberry (blueberry $\mathrm{R}^{2}=0.31$; lingonberry $\mathrm{R}^{2}=0.09$ ), suggesting that there might be differences in the direction of the relationships across site types (e.g., as a result of nonlinear relationships). To test for differences in plant responses by site type, we split our sites into two groups: one group with PC1 scores $>0$ (generally higher elevation sites with low soil moisture and high active layer depth [hereafter: upland]), and the other with PC1 scores $<0$ (generally low elevation with high soil moisture and low active layer depth [hereafter: lowland]) (Fig 3). Two sites (GSM4 and BFY6) were located near the center but both fell below PC1=0 so we grouped them with the lowland sites. We reran the models separately for each group. In all, we ran 6 models: an SEM for each species with ramets from all sites ( 2 models) and two for each species with only upland sites or only lowland sites (4 models). We did not force the regression equations in the SEM through zero to avoid interpreting beyond what we sampled. The SEMs were performed with the Analysis of Moment Structure statistical package (AMOS version 25.0) [53] which uses maximum likelihood estimation. We assessed model fit based on the ratio of minimum discrepancy to degrees of freedom (CMIN / df; ratio is between 1 and 5), root mean square error of approximation (RMSEA; lower $90 \%$ confidence interval is close to zero, 0.05 or lower), and the comparative fit index $(\mathrm{CFI}>0.90)$ [54]. 
Fig 3. PCA of environmental variables measured to encompass a $50 \times 60 \mathrm{~m}$ site. On PC1 elevation and active layer depth were positively correlated while soil moisture was negatively correlated. Sites were divided above and below PC1 $=0$ (grey and black dots) for analysis in the structural equation models, with PC1 <0 constituting "lowland" sites and PC1 >0 "upland" sites. Further details about the sites in S1 Table.

\section{Statistical Analyses: Allocation Patterns and Comparisons Between Species}

To evaluate whether canopy cover or stand history affected allocation to reproductive vs. vegetation biomass, we ran regressions of each of the biomass ratios (leaf mass to stem mass, number of flowers to leaf mass, and berry mass to leaf mass) against canopy cover or stand history for each species (for all sites and for upland and lowland sites separately). To determine whether blueberries were more variable at the within-site level than lingonberries we calculated the coefficient of variation in flower production and berry production for each species at all 17 sites and used a Student's t-test to test for differences between the two species. All statistical analyses other than SEMs were performed using base packages in R version 3.3.2 [51].

\section{Results}

\section{Pollen loads and berry production}

Blueberry produced more flowers per ramet than lingonberries, and were also more variable in flower production (blueberry mean $\pm \mathrm{SD}: 8.2 \pm 13.7$; lingonberry: $5.1 \pm 3.3$ ) Across all sites, $72 \%$ of blueberry flowers and $40 \%$ of lingonberry flowers were classified as well pollinated (Fig 4a; mean pollen load was 26 and 12 tetrads, respectively). For both species, upland sites had higher percentages of well-pollinated ramets than lowland sites (blueberry: $88 \%$ vs. $61 \%$; lingonberry: $55 \%$ vs. $24 \%$ ). In blueberry $24 \%$ of flowers produced fruit and in lingonberry $31 \%$ (Fig $4 b$ ). The mean number of berries produced per ramet at each site ranged from 0.08 to 9.83 (total berries per site: $0-118$ ) and 0 - 1.92 (total: $0-23$ ) for blueberries and 
lingonberries, respectively (Fig 4c). Upland sites produced more fruits than lowland sites for both species (Fig 4c).

Figure 4. a) Pollen load, b) fruit set, and c) number of berries produced, per ramet from all blueberry (Vaccinium uliginosum) and lingonberry ( $V$. vitis-idaea) ramets. Categories on the $\mathrm{x}$-axis are $V$. uliginosum lowland, $V$. uliginosum upland, $V$. vitis-idaea lowland and $V$. vitis-idaea upland. Boxplot midline is the median, the box is the third and first quartile, the whiskers extend up to 1.5 times the interquartile range from the top of the box to the furthest datum within that distance. Grey dots are the raw data.

\section{SEM model fit}

Our multi-group SEM, with all the ramets of each species included, fit poorly with none of the three metrics falling in the proper range (CMIN/df of 4.290 [good fit: 1-5], CFI was 0.806 [fit: $>0.90$ ], and RMSEA was 0.093 [90\%CI: 0.070 -0.118; fit: 0.05 inclusive])(Fig 5). The models using all sites explained $31 \%$ of the variation in blueberry fruit production but only $9 \%$ of lingonberry fruit production. When models were run separately for upland and lowland sites, fit statistics improved: CMIN/df was 2.735, CFI was 0.902 and RMSEA was 0.068 (90\% CI: 0.050 - 0.086); more paths were significant, and $\mathrm{R}^{2}$ values improved (Fig 6).

Fig 5. Structural equation model pathways for all sites combined. a) All blueberry (Vaccinium uliginosum) ramets, $\mathrm{n}=186$; b) All lingonberry ( . vitis-idaea) ramets, $\mathrm{n}=195$. Response variables outlined in bold. Solid lines represent significant pathways $(\mathrm{p}<0.05)$, while dashed lines are non-significant. Black lines represent positive pathways, while grey lines are negative pathways. Path coefficients are the standardized estimates from the multi-group structural equation model. $\mathrm{R}^{2}$ is for the number of berries. 
Fig 6. Final structural equation model pathways. a) upland blueberry, $\mathrm{n}=80$; b) lowland blueberry, $\mathrm{n}=106 ; \mathrm{c}$ ) upland lingonberry, $\mathrm{n}=97$; d) lowland lingonberry, $\mathrm{n}=98$. Response variables outlined in bold. Solid lines represent significant pathways, while dashed lines are non-significant. Black lines represent positive pathways, while grey lines are negative pathways. Path coefficients are the standardized estimates from the SEM. $\mathrm{R}^{2}$ is for the number of berries.

\section{Limitations for fruit production: flower numbers and pollen loads}

As expected, flower number had a positive effect on berry number for both species, although the relationship was much stronger for blueberry than for lingonberry (Fig 5). In contrast, pollen load had a clear positive impact on fruit number only in lingonberry (Fig 5). However, when the sites were divided into upland and lowland, the positive relationship between berry production and pollen load was only seen in the lowland sites in both species (Fig 6). Total floral resources were only important in the lowland model for lingonberry (Fig 6d), making this the only model in which both components of the pathway from total floral resources to pollen and pollen to berries were significant.

\section{Limitations for flower and fruit production: canopy cover}

In the SEM that included all sites the only significant effect of canopy cover was on blueberry flower production (a negative relationship; Fig 5a). Upland sites in our study had higher canopy cover than lowland sites ( $45 \pm 20 \%$ vs. $31 \pm 17 \%$ for blueberry sites and $49 \pm 19 \%$ vs. $35 \pm 18 \%$ for lingonberry sites; $\mathrm{F}_{(1,350)}=51.6, \mathrm{P}<0.001$ for all sites combined). When upland and lowland sites were evaluated separately, canopy cover had differing effects on flower production depending on the species and environment (Fig 6). In upland sites the relationship between canopy cover and flower number was negative in blueberries and positive in lingonberries while in lowland sites there was no relationship for either species. Canopy cover 
negatively influenced berry number at upland sites and positively influenced berry number in lowland sites for both blueberry and lingonberry (Fig 6).

Direct and indirect effects of stand history and geography

The only direct effects of stand history (PC2) were a positive relationship with flower production for the lowland lingonberry ramets and a positive relationship with berry production in lowland sites for both species (Figs 5,6), indicating that plants in older (burned longer ago) lowland sites were more productive. However, stand history had indirect effects as well: it was strongly positively related to canopy cover in upland sites, and negatively related to total floral resources in five out of six models (all except upland sites for lingonberry; Fig 6). As a result, the total impact of stand history was positive for lowland sites in both species (where positive direct effects outweighed negative indirect effects), but negative for upland blueberry sites and neutral for upland lingonberry sites (where negative indirect effects outweighed positive direct ones; Table 3). Geography (PC1) had no clear direct impacts on berry production, but indirect positive effects via flower production in lowland blueberry and upland lingonberry sites, and additional indirect effects via positive relationships with canopy cover in upland sites (Fig 6). Opposing effects resulted in weak total relationships between geography and berry production for all four models (Table 3).

\section{Most important drivers}

When looking at all sites, flower production had the greatest impact on blueberry production and pollen load on lingonberry production (Table 2). When ramets were split into upland and lowland sites, flower production was the most influential variable in all models, but other drivers differed (Table 3). For blueberry, canopy and stand history were second and third, but with opposite directions for upland sites (negative) and lowland sites (positive). For 
lingonberry, canopy cover and pollen loads were second or third, again with opposite directions

for canopy cover (negative in upland sites, positive in lowland sites).

Table 2. Direct and indirect effects on number of berries in each SEM shown in Figure 5 in order of the absolute value of the total effect.

\begin{tabular}{lccclccc}
\hline Blueberry & Direct & Indirect & Total & Lingonberry & Direct & Indirect & Total \\
\hline Flowers & 0.567 & -- & 0.567 & Pollen & 0.222 & 0 & 0.222 \\
Pollen & 0.088 & -- & 0.088 & Flowers & 0.175 & 0 & 0.175 \\
Canopy & 0.025 & -0.102 & -0.078 & Stand History & 0.131 & -0.037 & 0.094 \\
Geography & -0.139 & 0.063 & -0.076 & TFR & -- & 0.054 & 0.054 \\
Stand History & 0.081 & -0.086 & 0.006 & Geography & -0.139 & 0.019 & 0.012 \\
TFR & -- & -0.005 & -0.005 & Canopy & -0.028 & 0.018 & -0.011 \\
\hline
\end{tabular}

"Geography" refers to PC2 scores and "Stand History" to PC1 scores. "TFR" is total floral resources. Dashes indicate this link was not assessed in the model. 
bioRxiv preprint doi: https://doi.org/10.1101/796169; this version posted October 8, 2019. The copyright holder for this preprint (which was not certified by peer review) is the author/funder, who has granted bioRxiv a license to display the preprint in perpetuity. It is made available under aCC-BY 4.0 International license. 
Table 3. Direct and indirect effects on number of berries on SEMs by species and landscape type shown in Figure 6 in order of the absolute value of the total effect.

\begin{tabular}{|c|c|c|c|c|c|c|c|c|}
\hline & & Direct & Indirect & Total & & Direct & Indirect & Total \\
\hline & Blueberry & & & & Lingonberry & & & \\
\hline \multirow[t]{6}{*}{ Upland } & Flowers & 0.601 & -- & 0.601 & Flowers & 0.226 & -- & 0.226 \\
\hline & Canopy & -0.277 & -0.268 & -0.545 & Canopy & -0.273 & 0.054 & -0.219 \\
\hline & Stand History & 0.139 & -0.324 & -0.184 & Pollen & 0.191 & -- & 0.191 \\
\hline & Geography & 0.130 & -0.091 & 0.039 & Geography & -0.139 & 0.004 & -0.135 \\
\hline & Pollen & 0.021 & -- & 0.021 & TFR & -- & -0.030 & -0.030 \\
\hline & TFR & -- & $<0.001$ & $<0.001$ & Stand history & 0.112 & -0.121 & -0.009 \\
\hline \multicolumn{9}{|c|}{ Lowland } \\
\hline & Flowers & 0.405 & --0.405 & 0.405 & Flowers & 0.299 & -- & 0.299 \\
\hline & Canopy & 0.309 & -0.008 & 0.301 & Pollen & 0.257 & -- & 0.257 \\
\hline & Stand History & 0.237 & 0.008 & 0.245 & Canopy & 0.261 & -0.043 & 0.218 \\
\hline & Pollen & 0.209 & -- & 0.209 & Stand history & 0.224 & -0.051 & 0.173 \\
\hline & Geography & -0.085 & 0.189 & 0.103283 & Geography & -0.002 & 0.066 & 0.065 \\
\hline
\end{tabular}

"Geography" refers to PC2 scores and "Stand history" to PC1 scores. "TFR" is total floral resources. Dashes indicate this link was not assessed in the model. 


\section{Biomass allocation given canopy cover}

When ramets from all sites were included, relationships between canopy cover and allocation patterns were weak (Table 4), with only allocation to leaves (as measured by leaf mass to stem mass) showing an $\mathrm{R}^{2}>0.10$ (sites with higher canopy cover have lower allocation to leaves). In contrast, when we divided the ramets into the upland and lowland groups, there were multiple relationships for upland sites (Table 5a). In both blueberries and lingonberries in investment in leaves relative to stems decreased as canopy cover increased, while investment in berries relative to leaves decreased. Plants in lowland sites showed little change in allocation with canopy cover (Table 5b).

Table 4. The relationships between biomass ratios and canopy cover for all blueberry (Vaccinium uliginosum) and lingonberry ( $V$. vitis-idaea) ramets.

\begin{tabular}{|c|c|c|}
\hline Response variable ratios & Blueberry & Lingonberry \\
\hline Leaf mass : stem mass & $-0.0002, p=0.71$ & $-0.0213, p<0.001, R^{2}=0.11$ \\
\hline \# flowers : leaf mass & $-0.0893, p=0.084$ & $-0.4362, p=0.003, R^{2}=0.04$ \\
\hline Berry mass : leaf mass & $-0.0005, p=0.20$ & $0.0004, p=0.49$ \\
\hline
\end{tabular}

Parameter estimate and $\mathrm{p}$ values for all relationships. Significant $(\mathrm{p}<0.05)$ relationships are in bold and contain the adjusted $\mathrm{R}^{2}$ value. 
Table 5 The relationships between biomass ratios and canopy cover for blueberry (Vaccinium uliginosum) and lingonberry ( $V$. vitis-idaea) ramets in upland and lowland sites.

a) Upland

\begin{tabular}{|c|c|c|}
\hline Response variable ratios & Blueberry & Lingonberry \\
\hline Leaf mass : stem mass & $-0.0015, p=0.003, R^{2}=0.10$ & $-0.0079, p<0.001, R^{2}=0.24$ \\
\hline \# flowers : leaf mass & $-0.0584, p=0.342$ & $0.0367, p=0.73$ \\
\hline Berry mass : leaf mass & $-0.0021, p<0.001, R^{2}=0.16$ & $-0.0014, p=0.205$ \\
\hline \multicolumn{3}{|l|}{ b) Lowland } \\
\hline Response variable ratios & Blueberry & Lingonberry \\
\hline Leaf mass : stem mass & $0.0009, p=0.364$ & $-0.006, p=0.444$ \\
\hline \# flowers : leaf mass & $-0.0649, p=0.476$ & $-0.6259, p=0.0391, R^{2}=0.04$ \\
\hline Berry mass : leaf mass & $0.0006, p=0.348$ & $0.0007, p=0.280$ \\
\hline
\end{tabular}

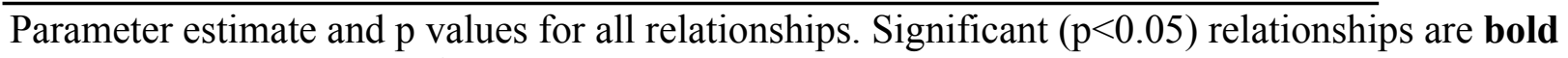
and contain the adjusted $\mathrm{R}^{2}$ value.

\section{Differences between species}

Canopy cover explained more than twice as much of the change in allocation to leaves in lingonberry as it did in blueberry $\left(\mathrm{R}^{2}=0.24\right.$ vs. $\left.\mathrm{R}^{2}=0.10\right)$. However, flowering rates in blueberry decreased rapidly with canopy cover (Fig 7a) while lingonberry flowering rates were unresponsive to canopy cover (Fig 7b).

Fig 7. The percentage of reproductive ramets at each site by the percentage of canopy cover at the site. a) blueberry ( $V$. uliginosum $) \mathrm{p}=0.007, \mathrm{R}^{2}=0.37, \mathrm{n}=15$; b) lingonberry $(V$. vitis-idaea $) \mathrm{p}$ $=0.998, \mathrm{n}=15$.

The variation in production of flowers and berries differed considerably across all 17 sites (S2 Table). However, while variation in flower production was greater in blueberries than in lingonberries (coefficient of variation: 0.87 vs. $0.33 ; \mathrm{t}=-5.79, \mathrm{p}=<0.001$ ), there was less 
evidence for a difference in variability in berry production (coefficient of variation: 1.57 vs.

$0.79 ; \mathrm{t}=-1.82, \mathrm{p}=0.096)$.

\section{Discussion}

Our primary goal in this research was to assess pollen versus resource (light and nutrient) limitation on berry production of blueberry and lingonberry across the landscape in black spruce of Interior Alaska. We found that the most important drivers of berry production differed between habitats and species. In general, lower elevation, wetter sites with shallower active layers tended to be more pollen limited than the upland, drier sites, while canopy cover was a strong predictor of berry production and allocation in upland but not lowland sites. Also, lingonberry plants tended to be more pollen limited than blueberry plants. These results suggest that the expected changes in boreal forest fire regime and subsequent effects on vegetation composition and soils are likely to have different impacts on productivity of blueberry and lingonberry, and different impacts in upland versus lowland habitat.

\section{Pollen limitation}

Lingonberries were more pollen limited than blueberries, especially in lowland sites (Table 3). Lingonberry is partially self-incompatible [55] and may be more dependent on pollinators for fertilization than blueberries. Factors other than self-incompatibility may also play a role: a much higher proportion of blueberries than of lingonberries were "well-pollinated" (pollen loads large enough to potentially fertilize all ovules), suggesting that either blueberries are more attractive to pollinators than lingonberries, or that they are more likely to occur in areas with high pollinator abundance. Additionally, flower number was more important in blueberry than in lingonberry in driving berry number, but that is likely simply the result of the much greater variability in flower number. 
Both species showed stronger evidence for pollen limitation in lowland sites than upland, and for lingonberry the total floral resources (number of flowers of all species in the immediate area) also played a positive role in lowland sites. Previous work by Spellman et al. [39] found canopy cover, total floral resources, and air temperature were all important in explaining $V$. vitisidaea pollination rates in black spruce sites but not mixed deciduous sites (analogous to our lowland and upland delineations). Overall, the results reinforce the idea that in cold, wet habitat the low abundance of pollinators limits fruit production.

\section{Resource limitation}

In upland sites canopy cover was a strong negative influence on both blueberry and lingonberry fruit production. High canopy cover may result in light limitation, though competition from tree and shrub species for nutrients and water may also play a role. The increased investment by both species in stems relative to leaves in upland sites as canopy cover increased is consistent with greater competition for light. The positive correlation between canopy and berry production in lowland sites for both species may be the result of variation in growing conditions at the small scale (around individual ramets), leading to high productivity in both Vaccinium and its neighboring species. This is supported by the higher blueberry fruit set (the ratio of berries to flowers) with higher canopy cover at low elevation sites. Overall, these results suggest that light limitation plays a larger role in upland sites, while nutrient limitation (the result of cold, wet soils) plays a larger role in lowland sites.

In upland blueberries, high canopy cover not only reduced berry number but also flower number. This is consistent with flower production of globe huckleberry $(V$. globulare $)$ in Montana, where reduced flower numbers were attributed to resource limitation above 30\% canopy closure [56]. Surprisingly, the relationship between canopy cover and flowers in upland 
lingonberries was positive, thereby somewhat mitigating the negative direct effects on berry

number. However, the negative relationship between canopy cover and blueberry flowers was almost twice the strength of the positive relationship between upland canopy cover and lingonberry flowers.

Stand history had a significant, positive effect on canopy cover in upland sites - the longer it had been since a fire, the more shrubs and trees had grown around the Vaccinium — but no relationship with canopy cover in lowland sites. This suggests that a major driver of variation in canopy cover is successional stage, while in lowland habitat other factors (such as local drainage conditions) drive variation. The different regeneration patterns were also found in the boreal black spruce forests of Quebec [57]. In that study, less productive sites (those with excess moisture) had slower rates of regeneration and a different community structure post fire than sites with drier conditions. These results suggest that increased fire frequency may have a positive effect on blueberry productivity in upland sites (through a reduction in canopy cover) but not in lowland sites (where older and high canopy-cover sites were most productive) nor in lingonberry (where stand history had a minimal impact).

\section{Differences between species in responsiveness}

We had predicted that blueberries would be more responsive to variation in the environment than lingonberries because of their more resource-acquisitive life history and shorter leaf lifespan. This was supported by the greater variability in flower number, blueberries being more limited by flowers production than lingonberries, and the much stronger relationship between proportion of ramets that were reproductive (produced at least one flower) and canopy cover (Fig 7). Blueberry responsiveness was also reflected in the greater ability of the SEMs to explain variation in berry production in blueberries. However, the importance of pollen 
limitation for lingonberry, especially in lowland sites, likely accounts for the much smaller difference between the two species in variability in berry production.

\section{Study limitations}

All measurements, except soil moisture and temperature, took place in a single growing season (in 2017). The 2017 growing season in Interior Alaska was warmer than normal, with temperatures in 2017 well above the long-term average for June $\left(17.1^{\circ} \mathrm{C}\right.$ vs. mean $15.4 \pm 1.5$ (SD) ${ }^{\circ} \mathrm{C}$ for $\left.1941-2010\right)$ and July $\left(18.7^{\circ} \mathrm{C}\right.$ vs. $16.6 \pm 1.3{ }^{\circ} \mathrm{C}$ ) (data from the Fairbanks International Airport obtained via the National Centers for Environmental Information). Furthermore, June was wetter than usual by about 25\% (43.9 $\mathrm{mm}$ in total, compared to a longterm average of $35.1 \mathrm{~mm}$ ). Interannual variation in temperature and precipitation are likely to affect pollinator activity and resource limitation. However, while this may result in changes in the absolute roles of these variables (e.g., a site that was not limited by pollinators in 2017 may be limited in a colder or wetter year), we expect the relative importance in the two different habitats (greater resource limitation in upland sites and greater resource limitation in lowland sites) and for the two different species (greater pollen limitation in lingonberry) to be consistent across years.

Both blueberry and lingonberry are clonal, but lingonberry can form dense mats of genetically identical ramets that share resources [1]. The trade-offs between vegetative and reproductive growth may not be occurring within a single ramet but across many connected ramets in an area. Additionally, lingonberry leaves last for several years, so trade-offs in allocation to leaves vs. flowers or fruits under changing environmental conditions are likely to be difficult to detect when all leaves are included in the analysis (as in this study). Future work should focus on trade-offs between flower and leaf initiation (both of which take place a year 
before flowering and leaf-out; CPH Mulder, pers. obs.) or between fruit production and leaf production in the following year.

Patterns in berry production and resource allocation were stronger in the upland sites. Lowland sites encompassed a greater range of site conditions, so it appears that environmental limitations were driven by something we missed in our study. Studies of Vaccinium species and boreal plant communities in Sweden have found soil $\mathrm{pH}$ and soil microbial activity play a role in community composition and Vaccinium biomass allocation [58-59]. Additionally, Interior Alaska contains a variety of wetland types with different combinations of water movement, soil type, and permafrost, all of which affect the plant communities above them [60-61]. Future work in Interior Alaska to elucidate the controls on Vaccinium productivity should follow examples of studies in Fennoscandia by including soil pH, direct measures of nutrient cycling, and wetland conditions.

Potential changes in berry production under an altered fire regime

The significance of canopy cover on berry production in the uplands leads to two potentially contrasting outcomes for future berry production in Interior Alaska. The change in forest fire dynamics caused by climate change is leading to an increase in fire size, severity, and frequency [15,28-29]. The increase in size and frequency will lead to a lower median stand age, generating canopy cover in the range most conducive to berry production $(<30 \%)$. Research in Russia and Montana has found berry production peaks 10-20 or 25-60 years after a wildfire, respectively $[56,62]$. Upland sites could see an increase in berry production under lower canopy cover. However, lowland sites may still be limited by pollinator abundance or other resources not associated with canopy. Additionally, fires are also changing in severity. More severe fires consume not just the plant communities above the soil but much of the soil organic layer itself 
[28], changing the immediate and long-term successional dynamics of the forest [63]. More

severe and more frequent fires create a new stable state of succession that instead of transitioning from hardwoods to spruce stays hardwood until the next fire [64-66].

In summary, our results show that both resource limitation and pollen limitation play a role in limiting fruit production of blueberries and lingonberries, with light limitation being a primary factor in upland sites while pollen limitation is important in lowland sites. We recommend that models predicting productivity under a changing climate incorporate pollinator availability as well as changes in resources.

\section{Acknowledgements}

We thank Jamie Hollingsworth, Mark Winterstein, Laila Brubaker, Tessa Hasbrouck, Alice Ramos de Moraes, Sean Lyons, and Eleanor Lynch for their help in the field, and Katie Spellman, Teresa Hollingsworth, and Diane Wagner for their constructive comments on earlier drafts. 


\section{References}

1. Hultén, E. Flora of Alaska and Neighboring Territories. Stanford: Stanford University Press; 1968.

2. Hupp J, Brubaker M, Wilkinson K, Williamson J. How are your berries? Perspectives of Alaska's environmental managers on trends in wild berry abundance. Int. J. Circumpolar Health. 2015; 74(1): 28704.

3. Weeden RB. Foods of rock and willow ptarmigan in central Alaska with comments on interspecific competition. Auk. 1969; 86: 271-81.

4. Hatler DF. Food habits of black bears in interior Alaska. Can. Field-Naturalist. 1972; 86(1): 17-31.

5. West SD. Dynamics of colonization and abundance in central Alaskan populations of the northern red-backed vole Clethryonomys rutilus. J. Mammal. 1982; 63:128-43.

6. Hupp JW, Safine DE, Nielson RM. Response of Cackling Geese to spatial and temporal variation in production of crowberries on the Alaska Peninsula. Polar Biol. 2013; 36(9): 1243-1255.

7. Stenset NE, Lutnæs PN, Bjarnadóttir V, Dahle B, Fossum KH, Jigsved P, et al. Seasonal and annual variation in the diet of brown bears Ursus arctos in the boreal forest of southcentral Sweden. Wildlife Biol. 2016; 22: 107-116.

https://doi.org/10.2981/wlb.00194

8. Alaska Department of Fish and Game (ADFG). Community Subsistence Harvest Information System. Available from www.adfg.alaska.gov/sb/CSIS/. [accessed 15 November 2018].

9. Kuchko AA. Bilberry and cowberry yields and the factors controlling them in the forests of Karelia, USSR. Acta Bot. Fenn. 1988; 136: 23-25.

10. Yudina VF, Maksimova TA. Dynamics of yielding capacity of small cranberry in southern Karelia. Russ. J. Ecol. 2005; 36: 239-242. doi:10.1007/s11184-005-0067-1.

11. Krebs, C. J., Boonstra, R., Cowcill, K., and Kenney, A.J. Climatic determinants of berry crops in the boreal forest of the southwestern Yukon. Botany. 2009; 87(4): 401-408.

12. Ihalainen M, Salo K, Pukkala T. Empirical prediction models for Vaccinium myrtillus and V. vitis-idaea berry yields in North Karelia, Finland. Silva Fennica. 2003; 37(1): 95108.

13. Tolvanen A. Aboveground growth habits of two Vaccinium species in relation to habitat. Can. J. Bot. 1995; 73(3): 465-473.

14. Barber QE, Bater CW, Braid AC, Coops NC, Tompalski, P, Nielsen SE. Airborne laser scanning for modelling understory shrub abundance and productivity. For. Ecol. Manage. 2016; 377: 46-54.

15. Weber MG, Flannigan MD. Canadian boreal forest ecosystem structure and function in a changing climate: impact on fire regimes. Environ. Rev. 1997; 5(3-4):145-166.

16. Yoshikawa K, Bolton WR, Romanovsky VE, Fukuda M, Hinzman LD. Impacts of wildfire on the permafrost in the boreal forests of Interior Alaska. J. Geophys. Res.: Atmos. 2002; 107(D1): FFR-4.

17. Yuan F, McGuire AD, Yi S, Euskirchen ES, Rupp TS, Breen AL, et al. Effects of future warming and fire regime change on boreal soil organic horizons and permafrost dynamics in Interior Alaska. In AGU Fall Meeting Abstracts; 2011. 
18. Rupp S, Breen A, Romanovsky V. The Integrated Ecosystem Model for Alaska and Northwest Canada. 2015 Apr 1. [cited 15 November 2018]. Available from http://arcticlcc.org/assets/factsheets/2010/IEM-CSC-Fact-Sheet-with-Supplement20150331.pdf.

19. Anstedt S. Rising Temperatures Trigger Ecological Changes in the Boreal Forest of Alaska. Fire Science Brief Issue 130. Boise: U.S. Joint Fire Science Program; 2011.

20. Scenarios Network for Alaska and Arctic Planning (SNAP) Projects, University of Alaska. [cited 15 November 2018]. Available from https://www.snap.uaf.edu/projects.

21. Johnson EA, Rowe JS. Fire in the subarctic wintering ground of the Beverley caribou herd. Am. Midl. Nat. 1975; 94(1): 1-14.

22. Stephenson AG. Flower and fruit abortion: proximate causes and ultimate functions. Annu. Rev. Ecol. Evol. Syst. 1981; 12(1): 253-279.

23. Charlesworth D. Evolution of low female fertility in plants: pollen limitation, resource allocation and genetic load. Trends Ecol. Evol. 1989; 4(10): 289-292.

24. Ehrlen J. Proximate limits to seed production in a herbaceous perennial legume, Lathyrus vernus. Ecology. 1992; 73(5): 1820-1831.

25. Viereck LA, Dyrness CT, Cleve KV, Foote MJ. Vegetation, soils, and forest productivity in selected forest types in interior Alaska. Can. J. For. Res. 1983; 13(5): 703-720.

26. Van Cleve K, Chapin FS, Dyrness CT, Viereck LA. Element cycling in taiga forests: state-factor control. BioScience. 1991; 41(2): 78-88.

27. Hollingsworth TN, Walker MD, Chapin III FS, Parsons AL. Scale-dependent environmental controls over species composition in Alaskan black spruce communities. Can. J. For. Res. 2006; 36(7): 1781-1796.

28. Kasischke ES, Turetsky MR. Recent changes in the fire regime across the North American boreal region - Spatial and temporal patterns of burning across Canada and Alaska. Geophys. Res. Let. 2006; 33(9).

29. Kasischke ES, Verbyla DL, Rupp TS, McGuire AD, Murphy KA, Jandt R, Barnes JL, Hoy EE, Duffy PA, Calef M, Turetsky MR. Alaska's changing fire regime-implications for the vulnerability of its boreal forests. Can. J. For. Res. 2010; 40(7): 1313-1324.

30. Messier C, Parent S, Bergeron Y. Effects of overstory and understory vegetation on the understory light environment in mixed boreal forests. J. Veg. Sci. 1998; 9(4): 511-520.

31. Wardle DA, Zackrisson O. Effects of species and functional group loss on island ecosystem properties. Nature. 2005; 435(7043): 806.

32. Reich PB, Wright IJ, Cavender-Bares J, Craine JM, Oleksyn J, Westoby M, Walters MB. The evolution of plant functional variation: traits, spectra, and strategies. International Journal of Plant Sciences. 2003; 164(S3): S143-S164.

33. Wright JP, Sutton-Grier A. Does the leaf economic spectrum hold within local species pools across varying environmental conditions? Funct. Ecol. 2012; 26(6):1390-1398.

34. Kevan PG, Tikhmenev EA, Usui M. Insects and plants in the pollination ecology of the boreal zone. Ecol. Res. 1993; 8(3): 247-267.

35. Davis AN, Holloway PS, Kruse JJ. Insect visitors and potential pollinators of lingonberries, Vaccinium vitis-idaea subsp. minus, in sub-arctic Alaska. Acta Hortic. 2003; 626: 441-446.

36. Holloway PS. Managing wild bog blueberry, lingonberry, cloudberry, and crowberry stands in Alaska. Fairbanks: University of Alaska Fairbanks and Natural Resource Conservation Service; 2006. 
37. Chittka L, Schürkens S. Successful invasion of a floral market. Nature. 2001; 411(6838): 653.

38. Boulanger-Lapointe N, Järvinen A, Partanen R, Herrmann TM. Climate and herbivore influence on Vaccinium myrtillus over the last 40 years in northwest Lapland, Finland. Ecosphere. 2017; 8(1): p.e01654.

39. Spellman KV, Schneller LC, Mulder CP, Carlson ML. Effects of non-native Melilotus albus on pollination and reproduction in two boreal shrubs. Oecologia. 2015; 179(2): 495-507.

40. Bishop JA, Armbruster WS. Thermoregulatory abilities of Alaskan bees: effects of size, phylogeny and ecology. Funct. Ecol. 1999; 13(5): 711-724.

41. Viereck LA, Little Jr EL. Atlas of United States Trees, Volume 2: Alaska Trees and Common Shrubs. Washington DC: United States Government Printing Office; 1975.

42. Viereck LA, Van Cleve K, Dyrness CT. Forest ecosystem distribution in the taiga environment. Forest ecosystems in the Alaskan taiga. New York: Springer; 1986. pp. 2243.

43. Chapin FS, Hollingsworth TN, Murray DF, Viereck LA, Walker MD. Floristic diversity and vegetation distribution in the Alaskan boreal forest. In: Chapin FS, Oswood MW, Van Cleve K, Viereck LA, Verbyla DL, editors. Alaska's changing boreal forest. New York: Oxford University Press; 2006; pp 81-99.

44. Ruess RW, Hollingsworth TN, Johnstone J. Vegetation composition for 84 sites in the Regional Site Network, compilation from previous surveys; 2015 [cited 2017 May 3]. Database: Bonanza Creek LTER - University of Alaska Fairbanks [internet]. Available from: http://www.lter.uaf.edu/data/data-detail/id/604

45. Allison SD, Treseder KK. Warming and drying suppress microbial activity and carbon cycling in boreal forest soils. Glob. Chang. Biol. 2008; 14(12): 2898-2909.

46. Van Cleve K, Yarie J, Erickson R, Dyrness CT. Nitrogen mineralization and nitrification in successional ecosystems on the Tanana River floodplain, interior Alaska. Can. J. For. Res. 1993; 23(5): 970-978.

47. Rennenberg H, Dannenmann M, Gessler A, Kreuzwieser J, Simon J, Papen H. Nitrogen balance in forest soils: nutritional limitation of plants under climate change stresses. Plant Biol. 2009; 11: 4-23.

48. Wrona FJ, Johansson M, Culp JM, Jenkins A, Mård J, Myers-Smith IH, et al. Transitions in Arctic ecosystems: Ecological implications of a changing hydrological regime. J. Geophys. Res.: Biogeosci. 2016; 121(3):650-674.

49. LTER Data Catalog - Bonanza Creek Long Term Ecological Research Site. [accessed 7 October 2017]. Available from http://ter.uaf.edu/data/data-catalog

50. Kearns CA, Inouye DW. Techniques for pollination biologists. Boulder: University Press of Colorado.

51. R Development Core Team. R: a language and environment for statistical computing. Vienna: R Foundation for Statistical Computing. 2016. Available from: http://www.Rproject.org/

52. Grace JB. Structural equation modeling in natural systems. Cambridge, UK: Cambridge University Press; 2006.

53. Arbuckle JL. Amos (Version 25.0) [Computer Program]; 2014. Chicago: IBM SPSS. 
54. Grace JB, Schoolmaster DR, Guntenspergen GR, Little AM, Mitchell BR, Miller KM, et al. Guidelines for a graph-theoretic implementation of structural equation modeling. Ecosphere. 2012; 3(8): 1-44.

55. Jacquemart AL, Thompson JD. Floral and pollination biology of three sympatric Vaccinium (Ericaceae) species in the Upper Ardennes, Belgium. Can. J. Bot. 1996; 74(2): 210-221.

56. Martin P. Factors influencing globe huckleberry fruit production in northwestern Montana. Bears Their Biol. Manage. 1983; 5: 159-165. http://dx.doi.org/10.2307/3872533.

57. Harper KA, Bergeron Y, Gauthier S, Drapeau P. Post-fire development of canopy structure and composition in black spruce forests of Abitibi, Québec: a landscape scale study. Silva Fennica. 2002; 36(1): 249-263.

58. Tyler G. Interacting effects of soil acidity and canopy cover on the species composition of field-layer vegetation in oak/hornbeam forests. Forest ecology and management. 1989; 28(2):101-14.

59. Kumordzi BB, Gundale MJ, Nilsson MC, Wardle DA. Shifts in aboveground biomass allocation patterns of dominant shrub species across a strong environmental gradient. PloS one. 2016 Jun 7;11(6):e0157136.

60. Hall JV, Frayer WE, Wilen BO. Status of Alaska wetlands. Anchorage: US Fish and Wildlife Service, Alaska Region; 1994.

61. McConnell NA, Turetsky MR, McGuire AD, Kane ES, Waldrop MP, Harden JW. Controls on ecosystem and root respiration across a permafrost and wetland gradient in interior Alaska. Environ. Res. Let. 2013; 8(4): 045029.

62. Mironov AD. Spatial and temporal organization of populations of the bank vole, Clethrionomys glareolus. Social systems and population cycles in voles. Basel: Birkhäuser; 1990. pp. 181-192.

63. Rupp TS, Starfield AM, Chapin FS, Duffy P. Modeling the impact of black spruce on the fire regime of Alaskan boreal forest. Clim. Change. 2002; 55(1-2): 213-233.

64. Flannigan MD, Logan KA, Amiro BD, Skinner WR, Stocks BJ. Future area burned in Canada. Clim. Change. 2005; 72(1-2): 1-16.

65. Mack MC, Treseder KK, Manies KL, Harden JW, Schuur EA, Vogel JG, Randerson JT, Chapin FS. Recovery of aboveground plant biomass and productivity after fire in mesic and dry black spruce forests of interior Alaska. Ecosystems. 2008; 11(2): 209-225.

66. Johnstone JF, Hollingsworth TN, Chapin FS, Mack MC. Changes in fire regime break the legacy lock on successional trajectories in Alaskan boreal forest. Glob. Chang. Biol. 2010; 16(4): 1281-1295. 
bioRxiv preprint doi: https://doi.org/101101/796169; this version posted October 8,2019 . The copyright holder for this preprint (which was not

\section{Supporting information}

S1 Table. Site names and descriptions. Upland sites are highlighted grey, lowland sites are white.

S2 Table. Coefficient of variation in flowers and berries produced for blueberries

(Vaccinium uliginosum) and lingonberries ( $V$. vitis-idaea) in each site. 


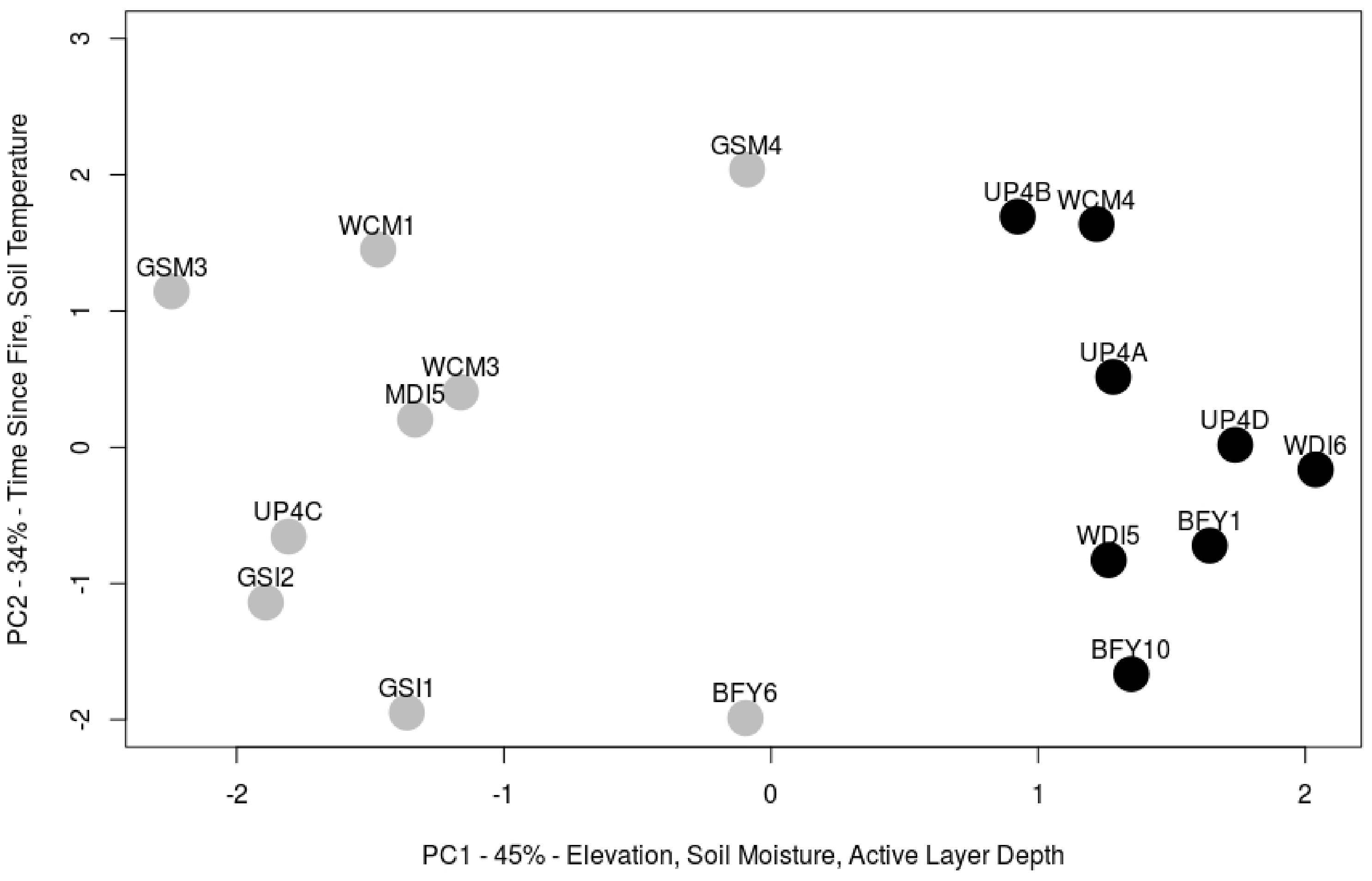

Figure 

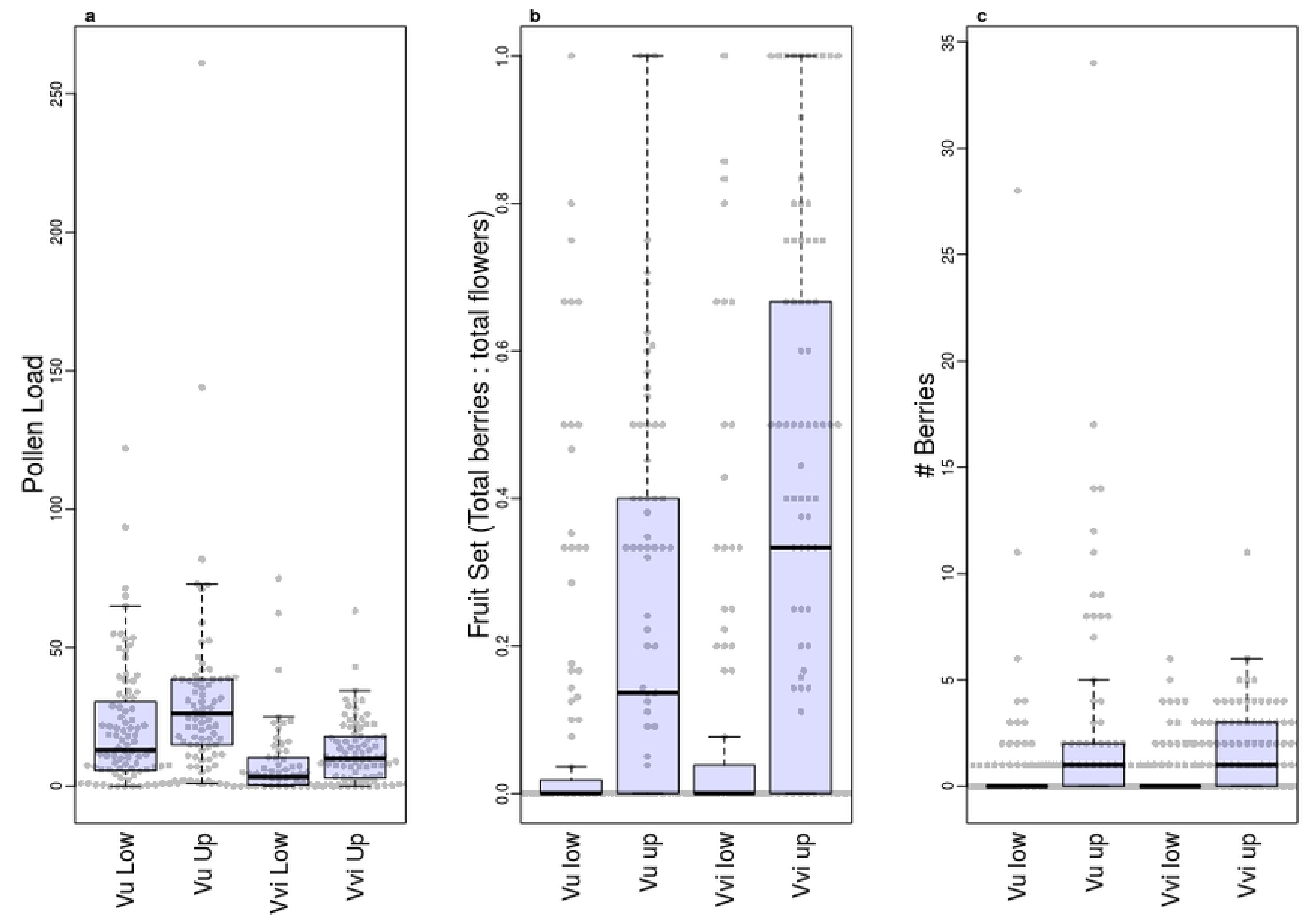

Figure 

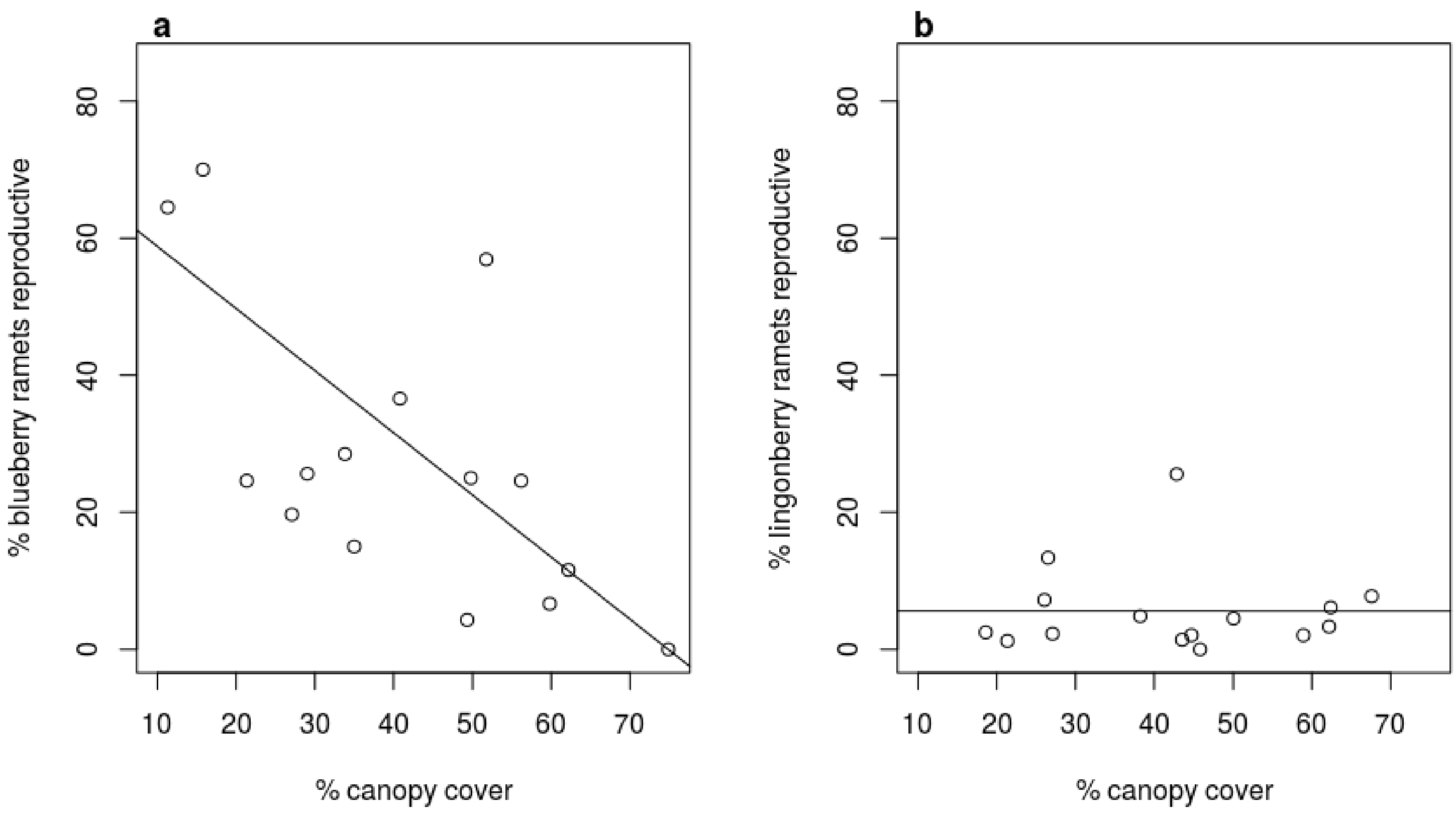

Figure 
a) Blueberry: $R^{2}=0.31$

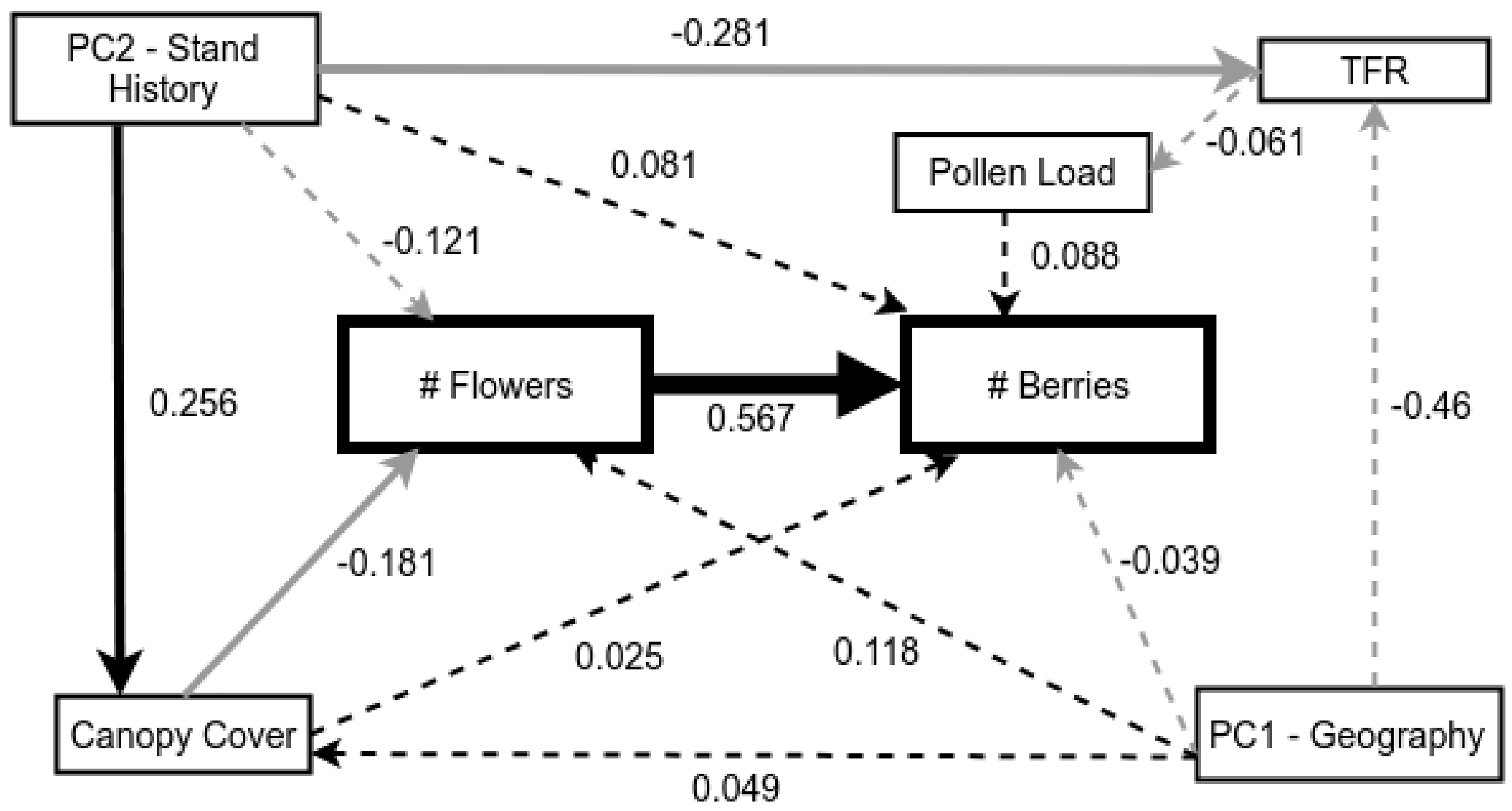

b) Lingonberry: $R^{2}=0.09$

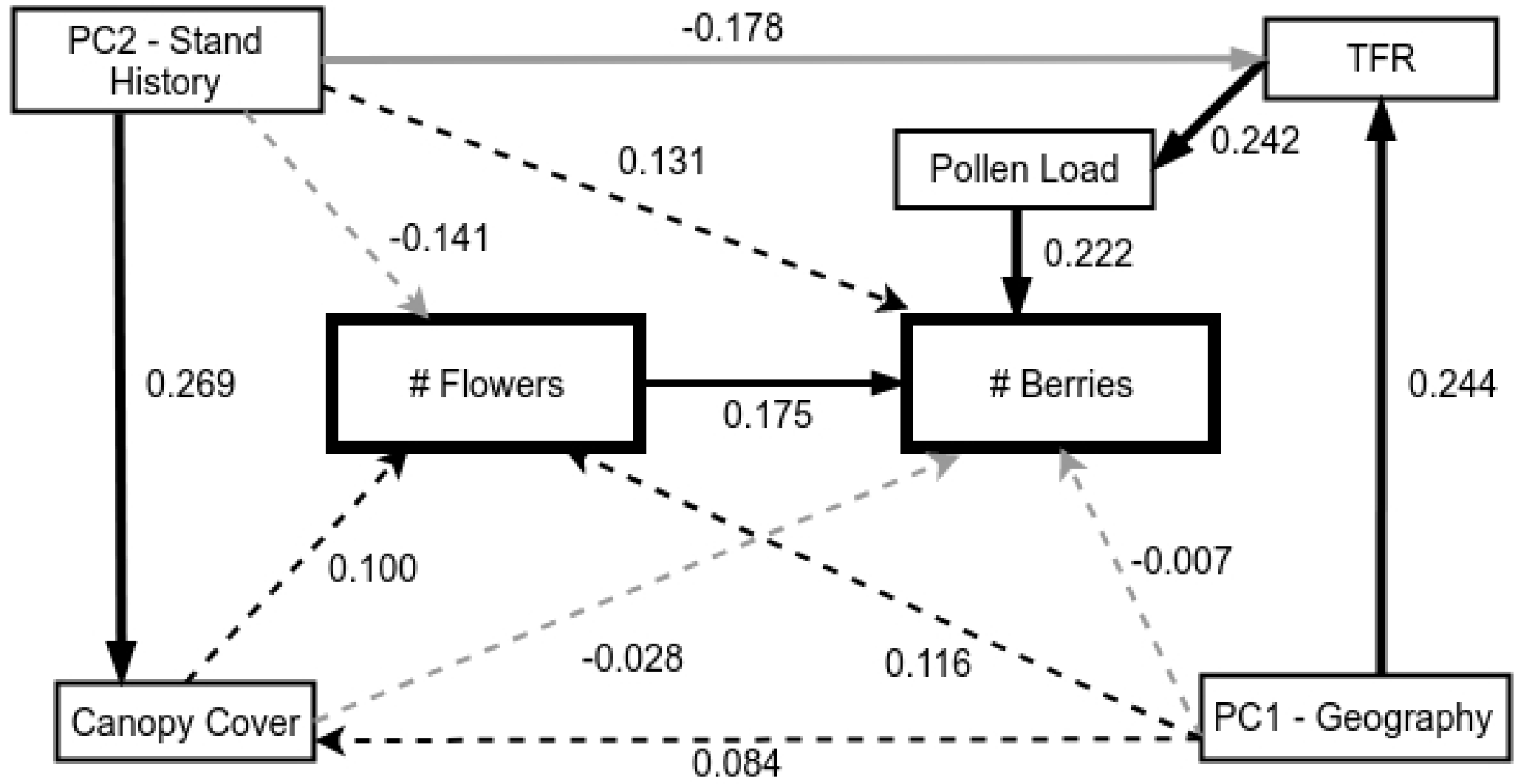

$F$ 
a) Blueberry upland: $R^{2}=\mathbf{0 . 5 5}$

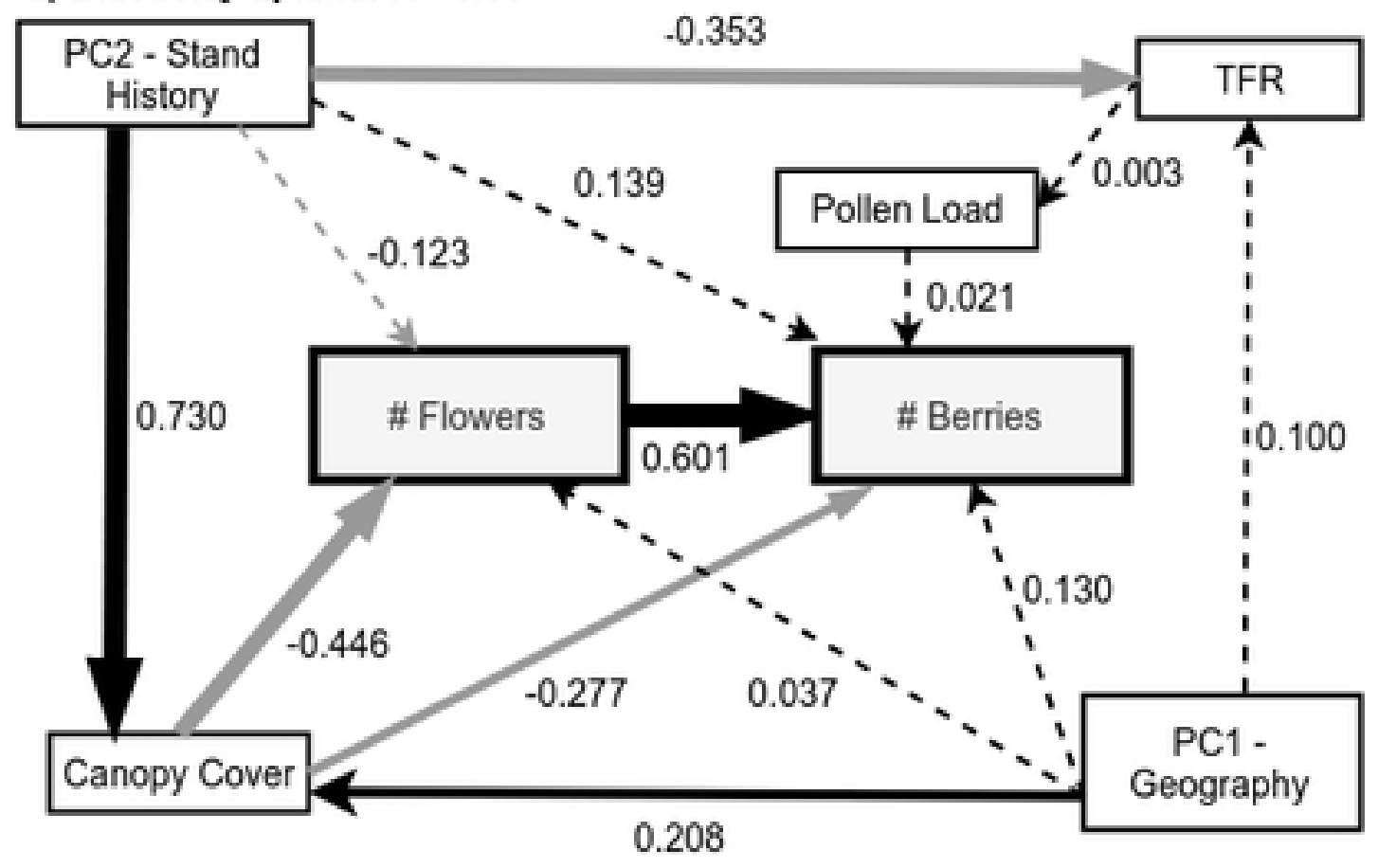

b) Blueberry lowland: $\mathbf{R}^{2}=\mathbf{0 . 3 5}$

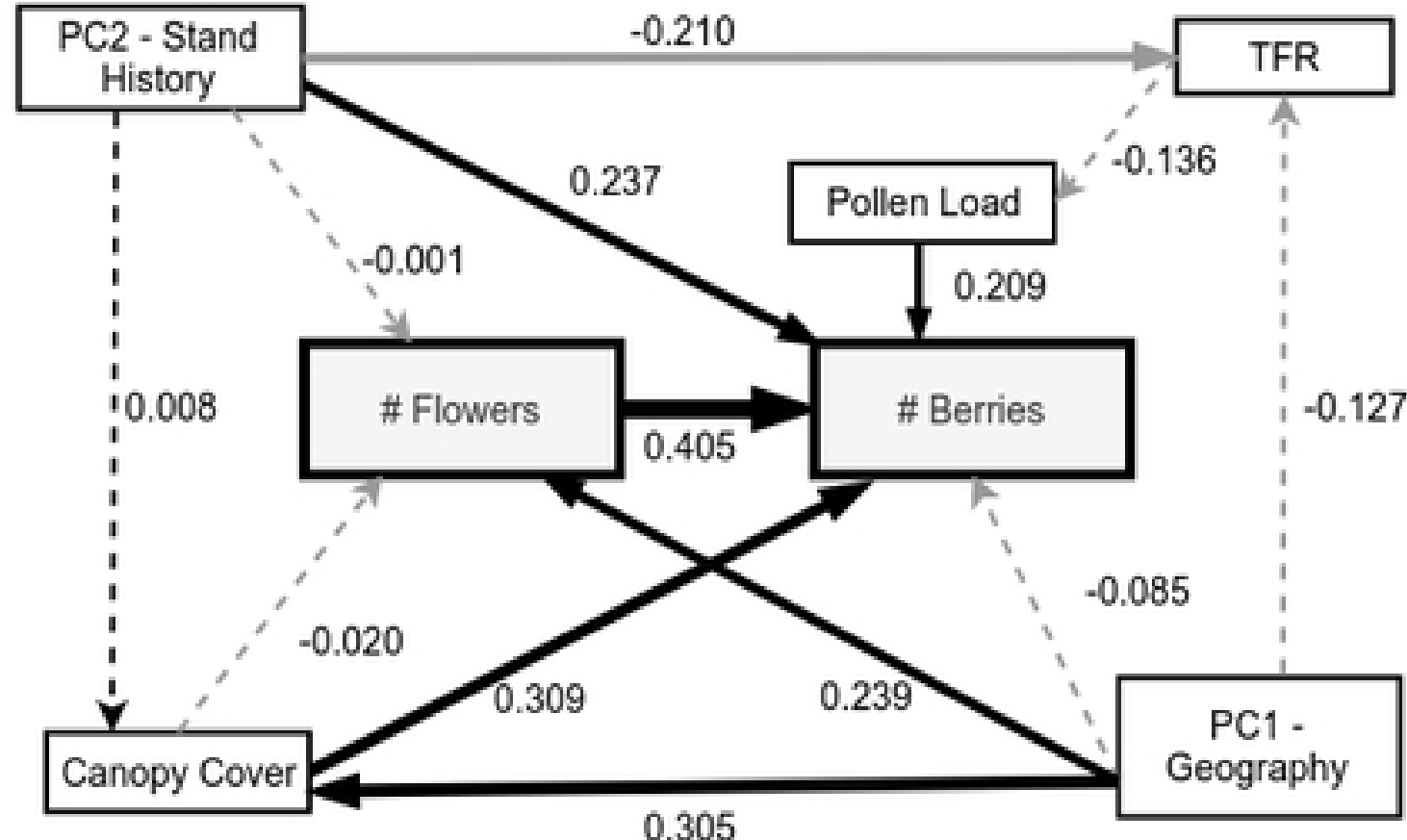

0.305 c) Lingonberry upland: $\mathbf{R}^{2}=\mathbf{0 . 1 2}$

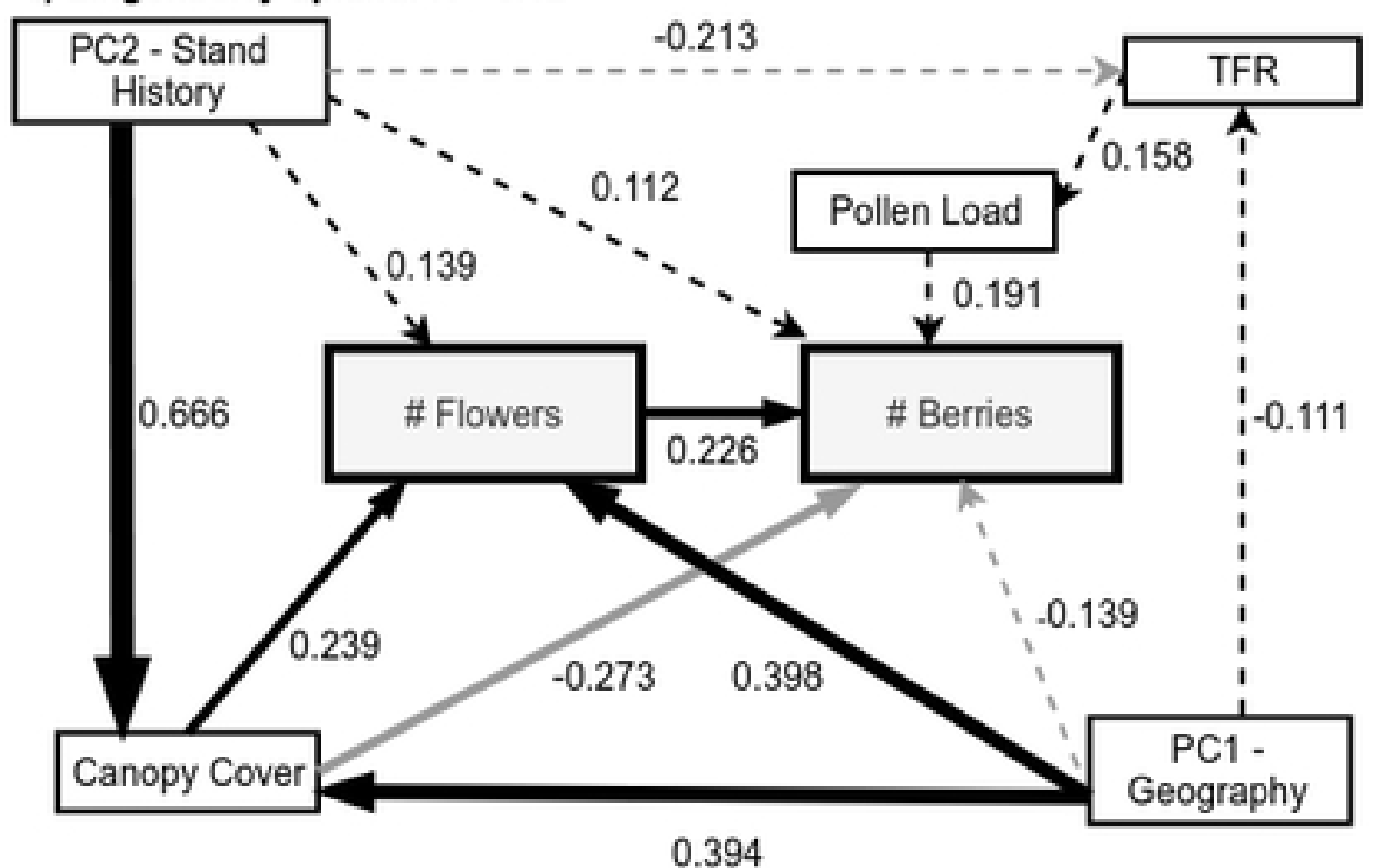

d) Lingonberry lowland: $R^{2}=0.21$

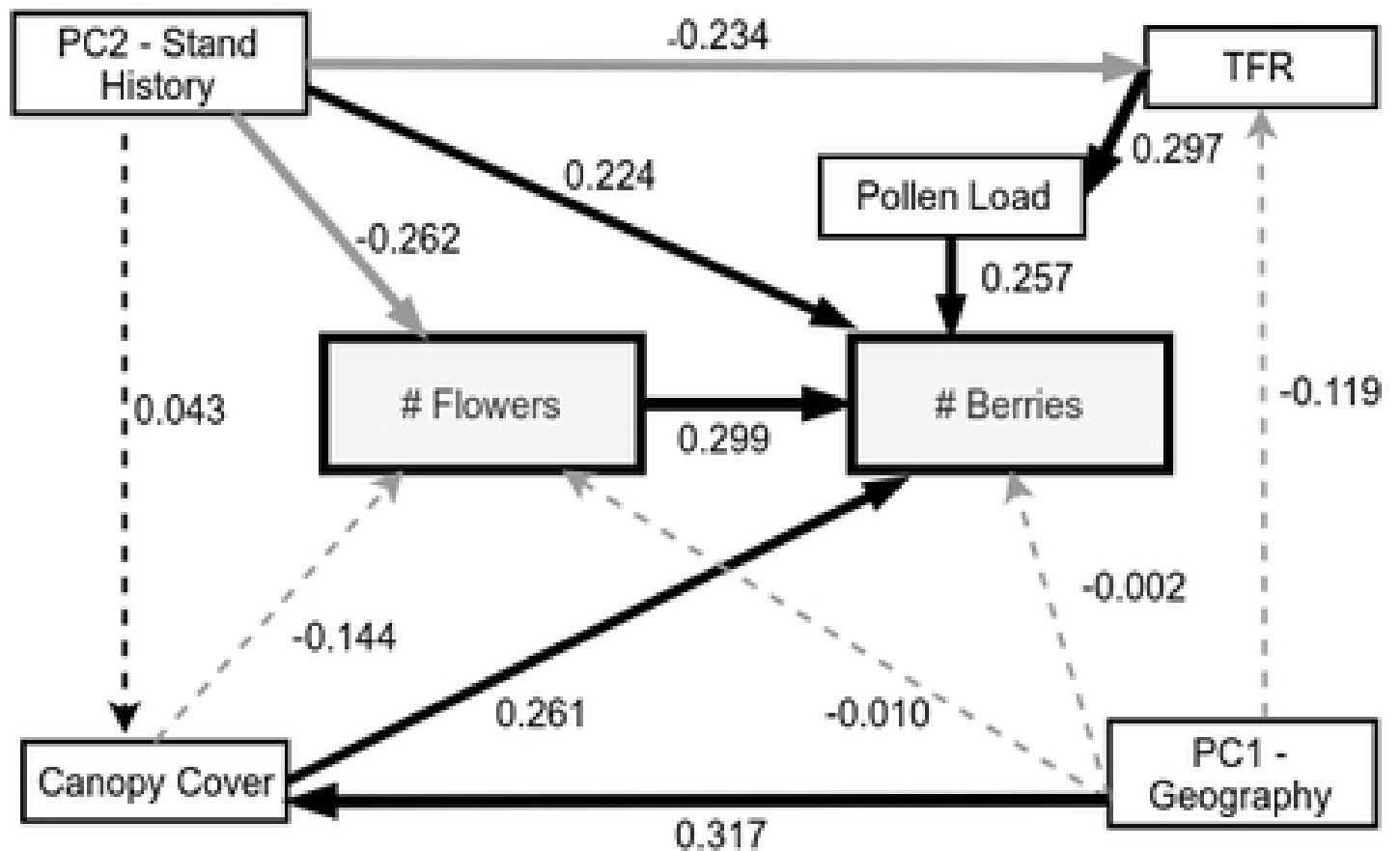


